\title{
Two genotypes of infectious bronchitis virus are responsible for serological variation in KwaZulu-Natal poultry flocks prior to 2012
}

\author{
Authors: \\ Adrian D. Knoetze $\mathrm{K}^{1,2}$ \\ Niloshni Moodley ${ }^{1}$ \\ Celia Abolnik ${ }^{2}$

\section{Affiliations:} \\ ${ }^{1}$ Rainbow Veterinary \\ Laboratory, Rainbow Chicken \\ Farms, South Africa \\ ${ }^{2}$ Department of Production \\ Animal Studies, University of \\ Pretoria, South Africa \\ Correspondence to: \\ Adrian Knoetze \\ Email: \\ adrian.knoetze@rcf.co.za \\ Postal address: \\ PO Box 42, Hammarsdale \\ 3700 , South Africa \\ Dates: \\ Received: 10 Feb. 2014 \\ Accepted: 03 June 2014 \\ Published: 09 Sept. 2014 \\ How to cite this article: \\ Knoetze, A.D., Moodley, N. \\ \& Abolnik, C., 2014, 'Two \\ genotypes of infectious \\ bronchitis virus are \\ responsible for serological \\ variation in KwaZulu-Natal \\ poultry flocks prior to 2012', \\ Onderstepoort Journal of \\ Veterinary Research 81(1), \\ Art. \#769, 10 pages. http:// \\ dx.doi.org/10.4102/ojvr. \\ v81i1.769

\section{Copyright:} \\ (C) 2014. The Authors. \\ Licensee: AOSIS \\ OpenJournals. This work \\ is licensed under the \\ Creative Commons \\ Attribution License. \\ Read online:

This study describes the isolation, serotyping and genotyping of 54 infectious bronchitis virus (IBV) cases predominantly in KwaZulu-Natal and compared to several isolates from other South African provinces between 2011 and 2012 and several historic isolates. The results indicate the division of isolates into two different genotypes of IBV within the province, Massachusetts (Mass)-like and QX-like. The IBV Mass-like genotype was the most prevalent and was detected in $79 \%$ of the full spike protein S1 gene sequences. Variation up to $22.3 \%$ was detected within local Mass-type strains, supporting the hypothesis that multiple IBV serotypes may co-circulate in the same region simultaneously. Additionally, more conservation was observed amongst Mass serotypes versus QX-like serotypes, implying that vaccine use can influence the variability within the IBV population; this is deduced from the fact that the only live vaccine registered for use in South Africa at the time of the study was of Mass origin and no QX-like vaccines were available for use. This study offers the first published consolidation of IBV isolates from an area of South Africa and identifies variation within the IBV population of the broiler flock within the study area over a 2-year period.

\section{Introduction}

Infectious bronchitis virus (IBV) is a highly contagious coronavirus of poultry that causes disease characterised by upper respiratory or urogenital lesions. IBV is a listed disease according to the World Organisation for Animal Health (OIE) and can result in large losses due to mortality or loss of production. The disease has a worldwide distribution. The virus is shed both through the upper respiratory system and in faeces and may be detected within the bird's gastrointestinal system for several weeks or months (Cavanaugh \& Naqi 1997). Clinical signs and lesions include respiratory symptoms, effects on egg production and egg shell quality and kidney pathology. Mortality rates vary between $14 \%$ and $82 \%$ depending on the IBV serotype and coinfections with other pathogens, particularly Escherichia coli and Mycoplasma spp. (Cavanaugh \& Naqi 1997; Cook 1983; Cook, Huggins \& Ellis 1991; Dhinakar Raj \& Jones 1997).

Coronaviruses are enveloped single-stranded positive-sense RNA viruses. The IBV genome is $27.569 \mathrm{kbp}$ in length and contains four coronavirus structural protein genes, spike (S), envelope (E), membrane $(\mathrm{M})$ and nucleocapsid $(\mathrm{N})$, plus non-structural protein genes 3 and 5 and its viral replicase gene (Rep). The order of these genes is 5' Rep-S-3-E-M-5-N 3' (Boursnell et al. 1987; Spaan, Cavanaugh \& Horzinek 1988). IBV S protein undergoes post-translational cleavage to S1 and S2 subproteins. The S1 protein is responsible for attachment to the host cell membrane and also has epitopes to which neutralising and haemagglutination-inhibiting antibodies bind (Kant et al. 1992; Koch et al. 1990). Two hypervariable regions (HVRs) have been demonstrated within the 50-159 residue regions of the S1 gene. HVR1 lies within region 38-51 whilst HVR 2 is located between amino acids 99 and 115 (Cavanaugh, Davis \& Mockett 1988; Cavanaugh et al. 1992; Wang, Xu \& Collisson 1997). A third HVR between amino acids 274 and 387 has also been described (Lee \& Jackwood 2001). The S1, S2 and M proteins have all been shown to induce cell-mediated immunity with the $\mathrm{N}$ gene proposed as carrying the predominant $\mathrm{T}$ cell epitope (Ignjatovic \& Galli 1994). The high degree of variability within the S1 gene has been attributed to the lack of proofreading by the viral RNA-dependent RNA polymerase and to recombination events during replication (Toro, Van Santen \& Jackwood 2012).

The emergence of variation within the IBV population has been widely described since 1951, when Jungherr, Chomiak and Luginbuhl (1956) demonstrated that the Connecticut isolate neither cross-neutralised nor cross-protected against the traditional H120 Massachusetts (Mass) isolate of the 1940s. The first published reports of IBV from South Africa were by Morley and Thompson in 1984. This was confirmed as an unknown variant by Cook et al. in 1999. These viruses 
were associated with swollen-head syndrome observed in infected flocks throughout southern Africa. Novel IBV has been described in Nigeria (De Wit, Cook \& Van der Heijden 2011) as well as Zimbabwe, where a QX-like IBV strain has been reported (Jackwood 2012).

The South African poultry industry is the single largest agricultural subsector, accounting for an annual turnover of R31.7 billion per annum (South African Poultry Association 2012) with flock sizes ranging from several hundred to large complexes of 600000 birds. Perdue and Seal (2000) listed the estimated losses per flock from an IBV infection as $10 \%$ to $20 \%$ of market value. This can devastate a poultry farm, where margins are relatively small. The economic impact of this disease is thus of great importance. Currently available research findings do not describe variation over a large collection of South African IBV isolates and thus do not adequately describe the degree of variation within the South African broiler flock. The core question revolves around the extent of variation present in the South African IBV population. Objectives of this study included identifying variation within IBV isolates, describing the correlation between serotyping and genotyping, as a method of variation identification and describing variation within the KwaZuluNatal IBV isolates over time.

\section{Materials and methods Sample collection}

Over 100 IBV isolates were collected during the 18-month period; 46 of these were selected for the present study based on clinical history and pathology caused by the strain, geographic distribution and serum neutralisation test results. In addition, eight prior isolates were also included in the study. These isolates included six Rainbow Veterinary Laboratory IBV reference strains and two historical isolates (Table 1). Seventy-five percent of isolates selected for the study originated from KwaZulu-Natal (KZN), 11\% from the North West province, 3.5\% each from the Eastern Cape and Gauteng and 6\% from the Western Cape. The weighting towards $\mathrm{KZN}$ isolates demonstrated the higher isolation rate from this province in addition to the higher suspected infection rate of this subpopulation within the study population.

\section{Virus isolation}

Samples for isolation were collected from postmortem samples on suspicion of IBV infection. Organs collected included either tracheal samples or pooled tracheal and kidney samples. Samples were collected from various postmortem facilities around South Africa but all virus isolations were performed at the KZN laboratory.

The standard virus isolation procedures are based on the published laboratory manual for the isolation, identification and characterisation of avian pathogens in 9 to 10-day-old embryonated chicken eggs via the allantoic sac inoculation route (Gelb 1989). Dead embryos were opened after candling; diagnosis of the cause of death was conducted and in the case of evidence that the embryo was infected with IBV, the allantoic fluid was collected. Typical signs of IBV infection in the embryo, namely stunting, urate deposits in the mesonephros and clubbing of the down feathers, were noted. In the cases where no pathological signs were seen in the embryo, the allantoic fluid was still collected and reinoculated for an additional passage. A total of three passages were performed until the sample was confirmed negative. Inoculations with supporting IBV clinical signs were confirmed for the presence of IBV through a chloroform inactivation test as well as diagnostic polymerase chain reaction (PCR) assay. The chloroform inactivation test differentiates between enveloped and non-enveloped viruses, and in combination with embryo pathology and haemagglutination tests a diagnosis of IBV can be made. PCR-confirmed IBV-positive allantoic fluid isolates were then stored at $-70{ }^{\circ} \mathrm{C}$ until further processing.

\section{Virus neutralisation tests}

Viral antigen-containing allantoic fluid was treated in serial dilution with antisera collected against each reference isolate (Gelb 1989). These antisera were produced through the hyperimmunisation of specific-pathogen-free leghorn chickens.

\section{RNA extraction and reverse transcription polymerase chain reaction}

RNA was extracted using Trisure reagent (Bioline) according to the procedure recommended by the manufacturer. A twostep PCR procedure was followed: viral cDNA was generated by combining $5 \mu \mathrm{g}$ of extracted RNA, $4 \mu \mathrm{L} 5 \mathrm{X}$ buffer (Roche), $1 \mu \mathrm{L}$ random hexamers (Roche), $2 \mu \mathrm{L}$ deoxynucleotides (dNTP) (Bioline), $0.3 \mu \mathrm{L}$ ribonuclease (RNAase) inhibitor (Affymetrix USB, 40U/ $\mu \mathrm{L}$ ), $0.5 \mu \mathrm{L}$ Molony murine leucosis virus (M-MuLV) reverse transcriptase (Roche) and diethylpyrocarbonate (DEPC) water $\left(\mathrm{H}_{2} \mathrm{O}\right)$ to a final reaction volume of $20 \mu \mathrm{L}$. The reaction was then incubated at $37^{\circ} \mathrm{C}$ for $60 \mathrm{~min}$.

Complementary DNA (cDNA) reactions were diluted by adding $20 \mu \mathrm{L}$ PCR-grade water (Roche). PCR was conducted with $10 \mu \mathrm{L} 2 \mathrm{X}$ Thermo Scientific Phusion Flash HighFidelity PCR master mix (Inqaba Biotech, Pretoria), $2 \mu \mathrm{L}$ Onderstepoort (OP) IBV S1 forward primer, $2 \mu \mathrm{L}$ OP IBV S1 reverse primer, $1 \mu \mathrm{L}$ PCR-grade $\mathrm{H}_{2} \mathrm{O}$ and $5 \mu \mathrm{L}$ cDNA. The target region was amplified in a Veriti thermal cycler (Life Technologies) using a cycling profile of $98^{\circ} \mathrm{C}$ for $10 \mathrm{~s}, 30$ cycles of $98^{\circ} \mathrm{C}$ for $5 \mathrm{~s}, 50^{\circ} \mathrm{C}$ for $15 \mathrm{~s}$ and an elongation phase of $72{ }^{\circ} \mathrm{C}$ for $2 \mathrm{~min}$. A final elongation step of $72{ }^{\circ} \mathrm{C}$ for 4 min was added. OP IBV S1 FOR: 5'-GAACAAAASACNGACTTAG-3', OP IBV S1 REV: 5'-CCATAACTAACATAAGGRCAA-3'.

PCR products were electrophoretically separated on a $1 \%$ agarose gel stained with ethidium bromide. A KAPA ${ }^{\mathrm{TM}}$ universal ladder was included to identify the 1700 bp S1 gene amplicon. Bands of the correct size were excised and DNA purified using QiaQuick PCR purification kit (Qiagen) following the recommended procedure. 
Purified 1.7 kb PCR amplicons were submitted to Inqaba Biotech (Pretoria) for Sanger sequencing. Results were edited using Chromas Lite and then aligned using BioEdit version 7.1.11 (Hall 1999). The Basic Local Alignment Search Tool (BLAST) server was used to retrieve similar sequences selected from Genbank for comparative analysis, together with important reference viruses. Pairwise similarity was calculated using BioEdit (Hall 1999) and phylogenetic trees were constructed in MEGA 5.2 (Tamura et al. 2011). Full
S1 gene sequences were deposited in Genbank under the accession numbers KJ200273-KJ200291. Partial sequences are available from the corresponding author on request.

Phylogenetic relationships were inferred using the neighbour-joining tree inference method with a Jukes-Cantor model of sequence evolution using MEGA 5.2 (Tamura et al. 2011). One thousand bootstrap samplings were performed to assign confidence values to branching orders.

TABLE 1: Infectious bronchitis viruses characterised in this study.

\begin{tabular}{|c|c|c|c|c|}
\hline Isolate & Province & Collection date & Serotype & Genotype \\
\hline CK/ZA/0890/81 & KwaZulu-Natal & May 1981 & Unknown & Mass $\dagger$ \\
\hline CK/ZA/0415/85 & KwaZulu-Natal & October 1985 & Unknown & Undetermined \\
\hline CK/ZA/mass/ & KwaZulu-Natal & Unknown & Mass & Undetermined \\
\hline CK/ZA/2034/99 & KwaZulu-Natal & 1999 & 793/B & Undetermined \\
\hline CK/ZA/0120/00 & North West & 2000 & Israel 1496-like & Undetermined \\
\hline CK/ZA/0269/01 & KwaZulu-Natal & 2001 & Israel 1496-like & Undetermined \\
\hline CK/ZA/2281/01 & KwaZulu-Natal & 2001 & 793/B & Undetermined \\
\hline CK/ZA/2287/11 & KwaZulu-Natal & April 2011 & Mass & Mass $\dagger$ \\
\hline CK/ZA/2754a/11 & North West & April 2011 & QX-like & Mass: \\
\hline CK/ZA/2754b/11 & North West & April 2011 & QX-like & Mass $\S$ \\
\hline CK/ZA/2754c/11 & North West & April 2011 & QX-like & Mass: \\
\hline CK/ZA/2312/11 & KwaZulu-Natal & April 2011 & Unclassified & QX-like§ \\
\hline CK/ZA/2953/11 & KwaZulu-Natal & May 2011 & Mass & Mass: $\$$ \\
\hline CK/ZA/3190/11 & KwaZulu-Natal & May 2011 & Mass & Mass $\dagger$ \\
\hline CK/ZA/3466/11 & Western Cape & June 2011 & QX-like & Undetermined \\
\hline CK/ZA/4015/11 & KwaZulu-Natal & June 2011 & Mass & Mass $\S$ \\
\hline CK/ZA/3809/11 & KwaZulu-Natal & June 2011 & Mass & Mass $\dagger$ \\
\hline CK/ZA/3665/11 & KwaZulu-Natal & June 2011 & QX-like & QX-like $\dagger$ \\
\hline CK/ZA/4421/11 & KwaZulu-Natal & July 2011 & QX-like & Mass末§ \\
\hline CK/ZA/4663/11 & KwaZulu-Natal & July 2011 & Mass & QX-like \\
\hline CK/ZA/4914/11 & KwaZulu-Natal & July 2011 & Mass & Mass: $\$$ \\
\hline CK/ZA/4916/11 & KwaZulu-Natal & July 2011 & QX-like & QX-like† \\
\hline CK/ZA/5250/11 & North West & July 2011 & QX-like & Mass $\dagger$ \\
\hline CK/ZA/5315/11 & KwaZulu-Natal & July 2011 & Mass & Mass $\dagger$ \\
\hline CK/ZA/5180/11 & KwaZulu-Natal & July 2011 & QX-like & Undetermined \\
\hline CK/ZA/5821/11 & KwaZulu-Natal & August 2011 & Mass & Undetermined \\
\hline CK/ZA/5815/11 & KwaZulu-Natal & August 2011 & Mass & Mass $\dagger$ \\
\hline CK/ZA/6056/11 & KwaZulu-Natal & August 2011 & Mass & Mass $\dagger$ \\
\hline CK/ZA/5741/11 & KwaZulu-Natal & September 2011 & Mass & Mass: $\$$ \\
\hline CK/ZA/6621/11 & KwaZulu-Natal & September 2011 & Mass & Mass $\dagger$ \\
\hline CK/ZA/6516/11 & KwaZulu-Natal & September 2011 & Mass & Mass $\dagger$ \\
\hline CK/ZA/6743a/11 & Western Cape & October 2011 & QX-like & Mass $\dagger$ \\
\hline CK/ZA/6743b/11 & Western Cape & October 2011 & QX-like & Mass $\dagger$ \\
\hline CK/ZA/7390/11 & KwaZulu-Natal & November 2011 & QX-like & Undetermined \\
\hline CK/ZA/7388/11 & KwaZulu-Natal & November 2011 & QX-like & Undetermined \\
\hline CK/ZA/6917/11 & KwaZulu-Natal & November 2011 & QX-like & Undetermined \\
\hline CK/ZA/8306/11 & North West & December 2011 & QX-like & Undetermined \\
\hline CK/ZA/0772/12 & KwaZulu-Natal & February 2012 & Unclassified & Undetermined \\
\hline CK/ZA/1272/12 & Gauteng & February 2012 & Mass & Undetermined \\
\hline CK/ZA/1264/12 & Gauteng & February 2012 & Mass & Undetermined \\
\hline CK/ZA/1863/12 & KwaZulu-Natal & April 2012 & TC07-like & Undetermined \\
\hline CK/ZA/1490/12 & KwaZulu-Natal & April 2012 & Mass & Undetermined \\
\hline CK/ZA/1458/12 & KwaZulu-Natal & April 2012 & QX-like & Undetermined \\
\hline CK/ZA/4869/12 & Eastern Cape & October 2012 & QX-like & Undetermined \\
\hline $\mathrm{CK} / \mathrm{ZA} / 4871 / 12$ & Eastern Cape & October 2012 & QX-like & QX-like $\dagger$ \\
\hline CK/ZA/6089/12 & KwaZulu-Natal & October 2012 & QX-like & Mass \\
\hline CK/ZA/6573/12 & KwaZulu-Natal & October 2012 & Unclassified & Undetermined \\
\hline CK/ZA/6720/12 & KwaZulu-Natal & October 2012 & QX-like & QX-like† \\
\hline CK/ZA/6689/12 & KwaZulu-Natal & October 2012 & QX-like & Undetermined \\
\hline
\end{tabular}

$\dagger$, full S1 gene sequence; $\$$, partial 3 ' sequence; $\S$, partial $5^{\prime}$ sequence. 


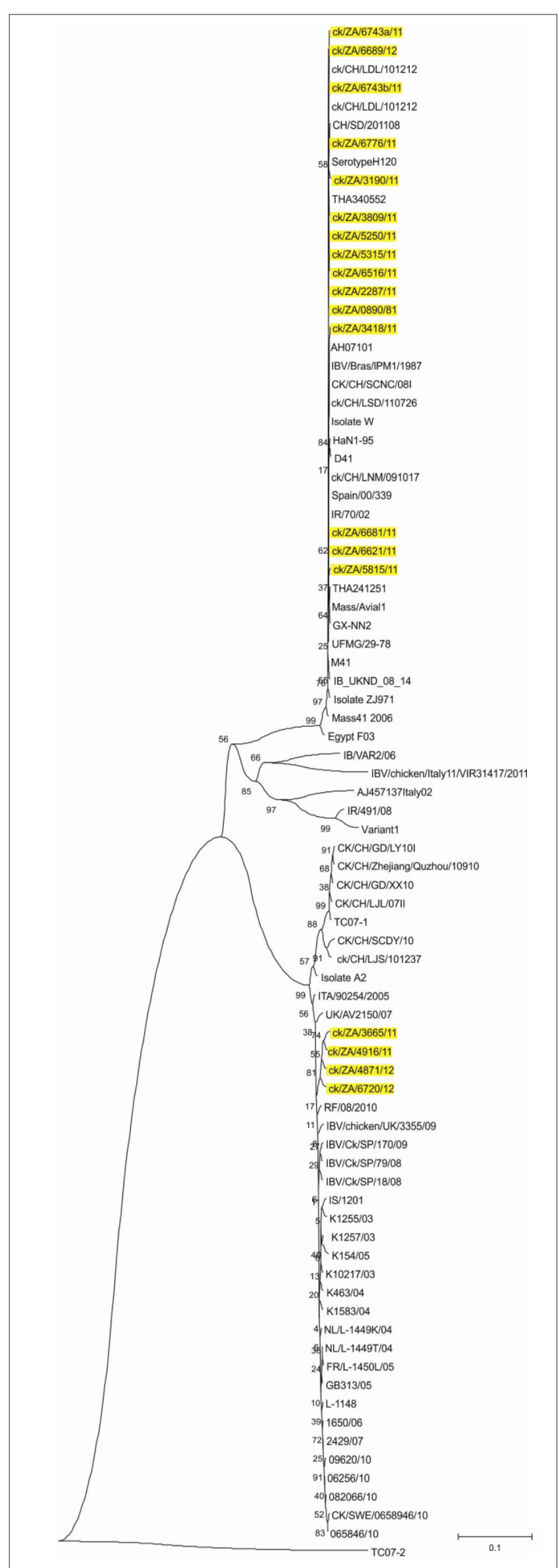

FIGURE 1: Phylogenetic tree of full S1 gene nucleotide sequences (1665 bp) with isolates sequenced in this study highlighted.

\section{Ethical considerations}

This study was approved by the University of Pretoria's Animal Ethics Committee under reference number V006/12.

\section{Results}

A total of 54 isolates confirmed as IBV positive by serum neutralisation and diagnostic PCR were analysed by reverse transcription polymerase chain reaction (RT-PCR). The isolates were named in accordance with the system proposed by Cavanaugh (2001) (Table 1).

Forty-one samples produced a band of approximately 1700 base pairs (data not shown), of which full S1 gene sequences could be assembled for 19 isolates, with the remainder generating either partial forward or reverse sequences. Despite numerous attempts on the service provider's part to troubleshoot sequencing reactions, they were unable to generate the complementary forward or reverse reactions for 30 of the amplicons submitted. The reasons for this are unknown, since the exact same forward and reverse primers were used for sequencing as for RT-PCR, and numerous re-submissions of fresh amplified RT-PCR product in sufficient molar quantities were made. Phylogenetic analysis of the full S1 gene sequences are presented in Figure 1. Partial sequence trees are not shown, but were used to genotypically classify the isolates (results are presented in Table 1). Isolates were classified as either QX-like $(n=4)$ or Mass-type $(n=16)$.

S1 gene nucleotide sequence comparisons (data not shown) revealed variability in QX-like isolates $\mathrm{CK} / \mathrm{ZA} / 3665 / 11$, CK/ZA/4916/11, CK/ZA/4871/12 and CK/ZA/6720/12 when compared to a standard H120 Mass serotype with a high number of base changes observed at positions 95-119, 142-148,165-172 and 695-708. This was evident in the translated amino acid sequences (Figure 2), and notably between residues 58 and 62 of these isolates where ISSES is replaced with STNHT.

In this QX-like group, residues 77-85 contained the motif KDVYNQSVA compared to the Mass grouping with a motif of HGGRVVNA. A large insertion was also detected between residues 122 and 129 with a motif of SSGSGSCP, which is not present in any of the Mass-type isolates. Two point mutations within CK/ZA/3665/11 resulted in the replacement of asparagine with histidine at position 24 and then aspartic acid with tyrosine at position 248. Variation was observed between the two 2011 and the 2012 isolates within the QX-like group; the protein sequence at position 18-22 of the 2012 isolates was FALWK and CALCS as compared to the 2011 isolates at the same position. The most variable portion of the amino acid sequence for this group occurred at residue 400 , where two of four isolates had consensus and variation between asparagine, histidine and tyrosine was seen.

The remaining isolates were closely related to reference sequence H120 (Mass serotype). Single-point mutations were observed at various points across the isolates. No variation in 


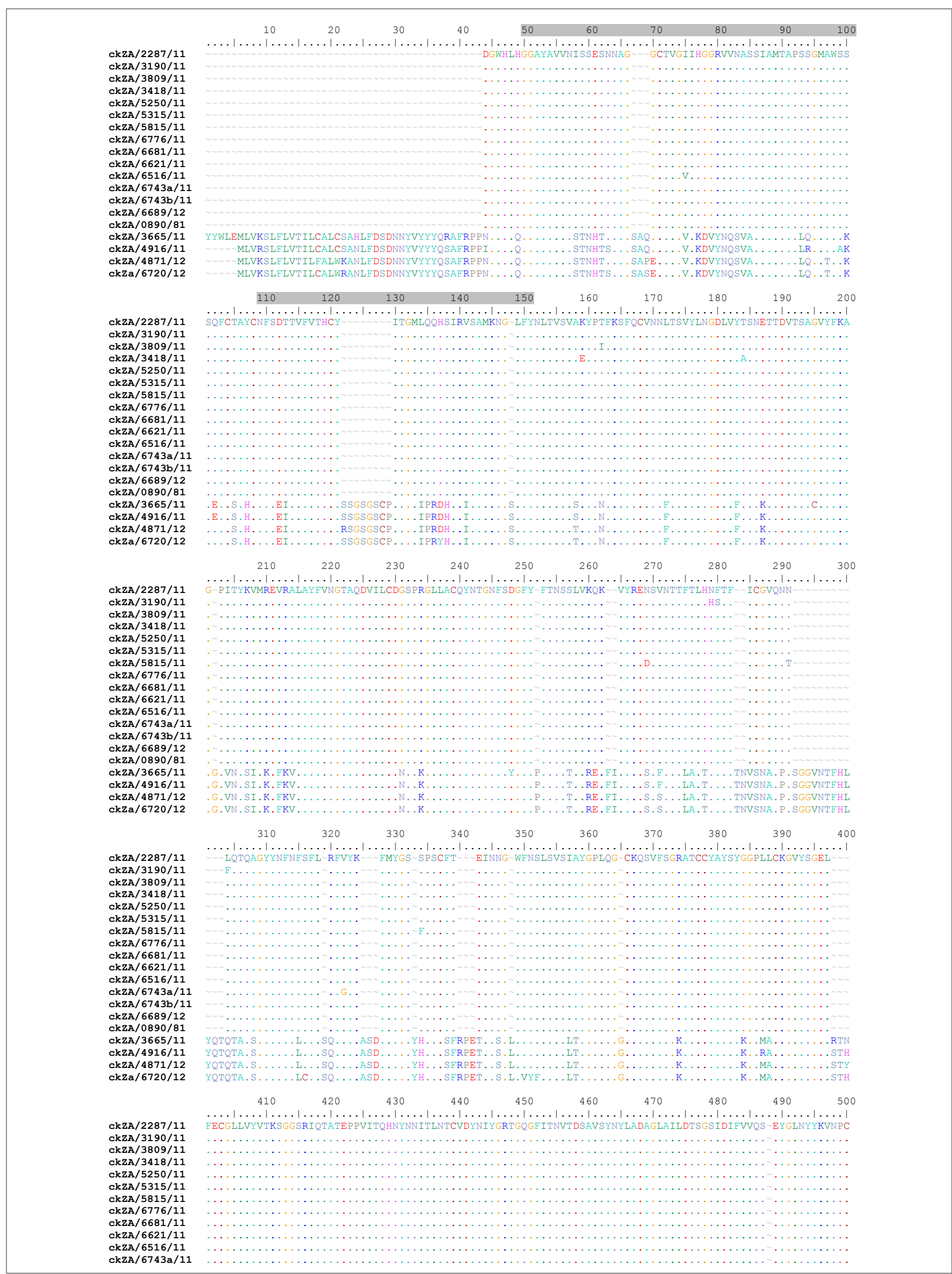

FIGURE 2: Multiple amino acid sequence alignment for full S1 proteins. Hypervariable regions are indicated in grey. The first sequence is used as a reference and identities are plotted as ".. 


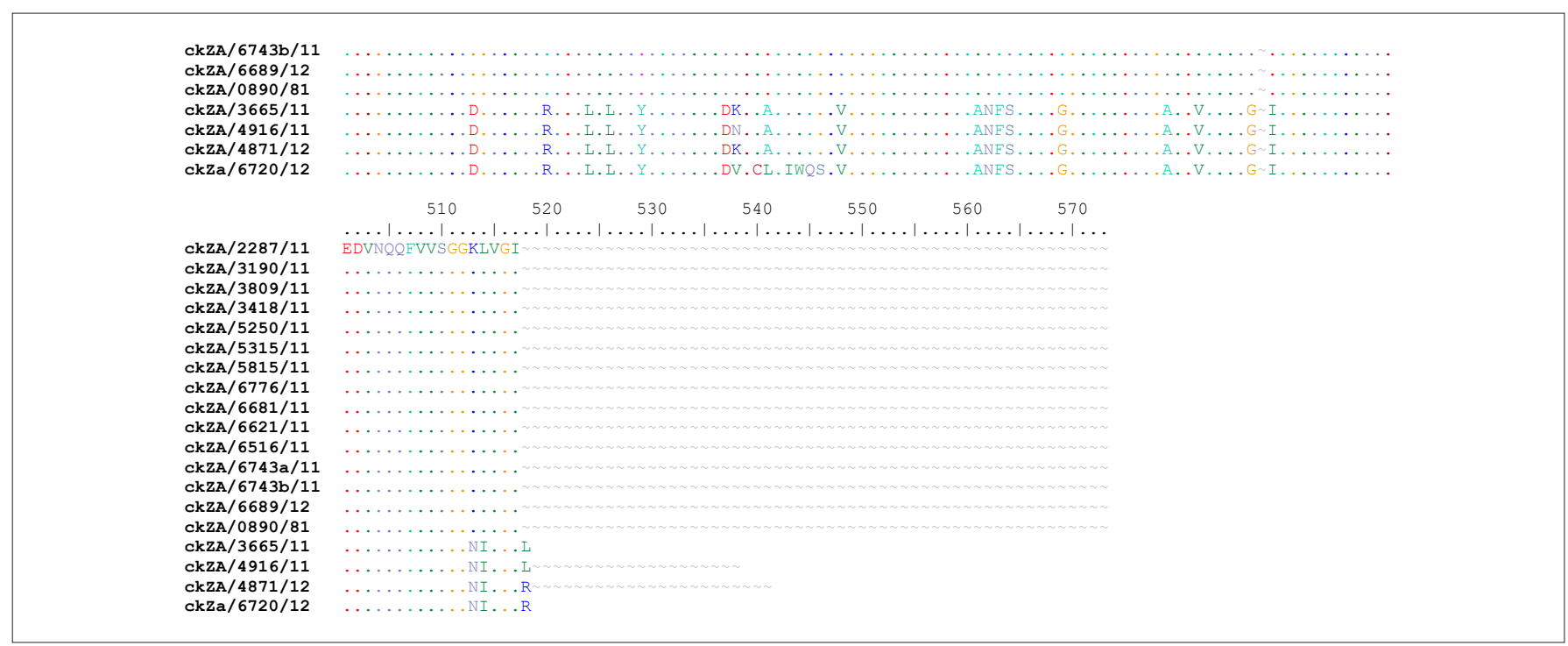

FIGURE 2 (Continues...): Multiple amino acid sequence alignment for full S1 proteins. Hypervariable regions are indicated in grey. The first sequence is used as a reference and identities are plotted as "..

nucleotide sequence is seen after base pair 792, demonstrating greater conservation in the second half of the gene.

Pairwise similarities were calculated between the study isolates (Table 2) and selected serotype sequences obtained from Genbank (Table 3). Pairwise comparisons against reference sequences support the description of two distinct groups of isolates. QX-like isolates shared $97.2 \%-98.4 \%$ nucleotide sequence identities, corresponding to $97.6 \%-98.8 \%$ identity at the amino acid level. These QX-like isolates only shared $77.7 \%-79 \%$ nucleotide sequence and $85.9 \%-88.6 \%$ amino acid sequence identities with the Masslike isolates. Sequence variation within the Mass-like group was less, at $98.9 \%-100 \%$ and $99 \%-100 \%$ nucleotide and amino acid similarities respectively (Table 2). Four isolates (CK/ZA/0890/81, CK/ZA/6689/12, CK/ZA/5315/11 and $\mathrm{CK} / \mathrm{ZA} / 2287 / 11)$ were very closely related. These sequences differed by $0.3 \%$ or four point mutations at positions 294,302 , 374 and 483.

The remainder of the Mass-type South African isolates shared high degrees of similarity with two point mutations common to all isolates when compared to the reference strain. The replacement of thymine with cysteine at residue 11 and thymine with adenine at residue 138 was found amongst all Mass isolates. The highest frequency of variation in this case was found between base pairs 706 and 818, with 10-point mutations found in this region.

These two distinct groupings were also evident when local strains were compared to international reference strains (Table 3). CK/ZA/3665/11, CK/ZA/4916/11, CK/ $\mathrm{ZA} / 4871 / 12$ and $\mathrm{CK} / \mathrm{ZA} / 6270 / 12 \mathrm{~s}$ shared the highest nucleotide and amino acid homology with IBV QXlike Chinese TC07-1 and UK 3355/09 strains. The South African Mass-type viruses shared 99.2\% - 99.7\% nucleotide sequence identity and $96.5 \%-96.7 \%$ amino acid similarity with isolate Mass Avail.

\section{Discussion}

Phylogenetic analysis of the S1 genes revealed two distinct groupings of IBV within the study isolates. The larger group contained 15 of the initial 19 full sequences and shared $99.0 \%-99.7 \%$ amino acid sequence similarity with the H120 serotype. Within this group there was $98.8 \%-100 \%$ similarity at the nucleotide sequence level. Reported S1 gene mutation rates under vaccine selective pressure are 2.5\% (Lee \& Jackwood 2001) and reports suggest that in the absence of a selective vaccine, mutation rates are twice as high than when under selective pressure (McKinley et al. 2011).

When compared against the year or area of isolation it was found that the highly similar Mass grouping originated from KZN between April 2011 and September 2011 and then again in October 2012. One isolate from the North West province from July 2011 and two from the Western Cape collected in October 2011 also fell within this group. Strong correlations were observed between the isolates that originated outside KZN. Despite the geographic areas being far apart there was movement of eggs and embryos between provinces during the study period. The variability of $0.4 \%$ observed between $\mathrm{CK} / \mathrm{ZA} / 6743 \mathrm{a} / 11$ and $\mathrm{CK} / \mathrm{ZA} / 6743 \mathrm{~b} / 11$ is interesting, since these samples were collected from the same farm on the same day but originated from separate chicken houses or units. The existence of an insertion at 673 and point mutations at 4, 6, 296 and 879 demonstrate the existence of variability and selection of subpopulations on a single farm. The selective criteria for these subpopulations are unknown, but variables such as maternally derived antibody levels and timing of vaccination could apply greater selective pressure for the emergence of variants of the epitopes found on vaccinederived viruses (De Herdt et al. 2001; Meulemans et al. 2001; Mondal \& Naqi 2001). An alternative hypothesis is that the individual house conditions with regard to air quality and the degree of damage to the chicken's tracheal epithelium and cilia affect the selection of S1 protein subpopulations. 


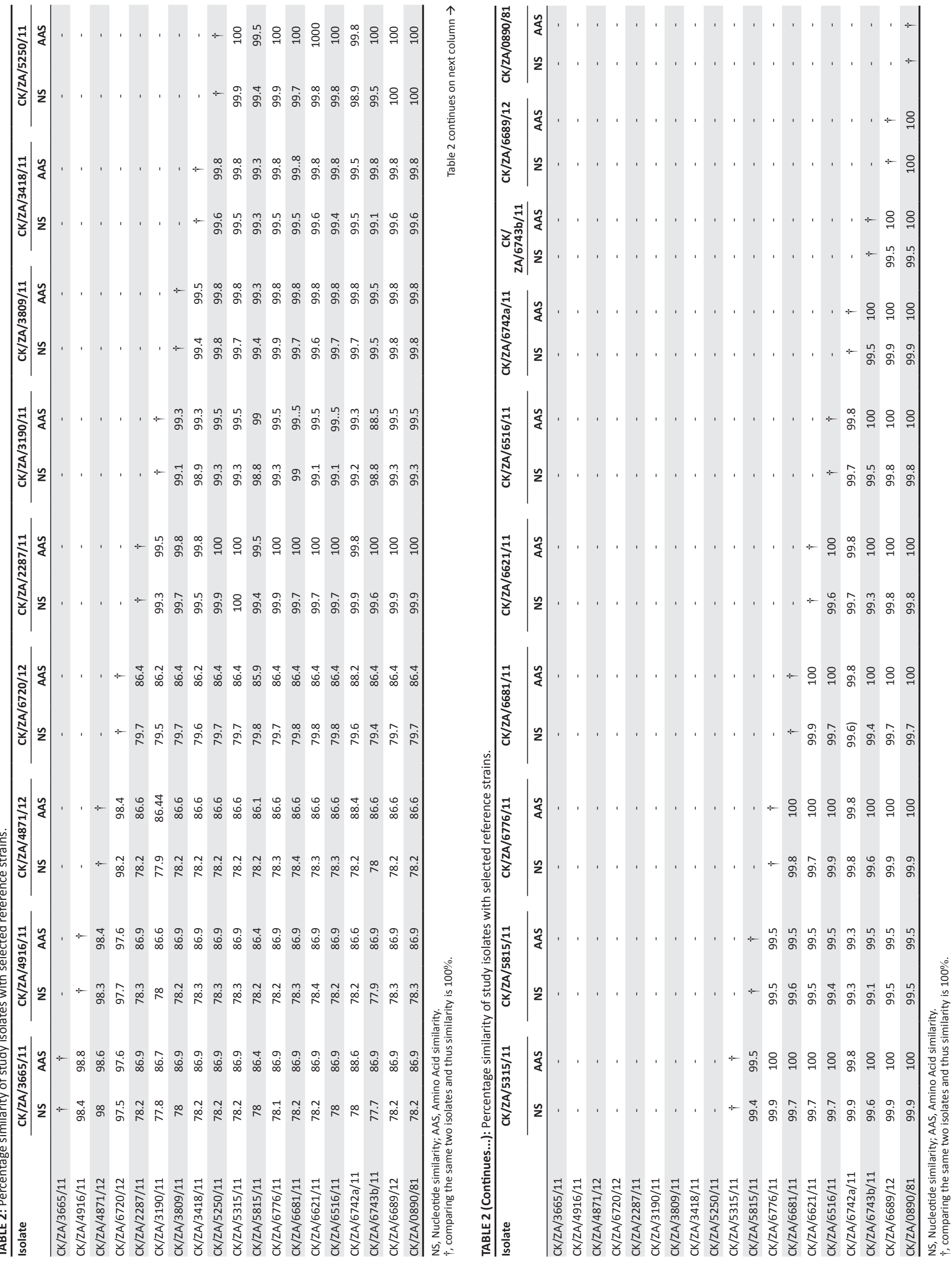


TABLE 3: Percentage similarity of study isolates with selected reference strains.

\begin{tabular}{|c|c|c|c|c|c|c|c|c|c|c|c|c|c|c|c|c|c|c|}
\hline \multirow[t]{3}{*}{ Study isolate } & \multirow{2}{*}{\multicolumn{2}{|c|}{$\begin{array}{c}\text { QX-like: } \\
\text { ChickenUK } \\
3355 / 09\end{array}$}} & \multirow{2}{*}{\multicolumn{2}{|c|}{$\begin{array}{l}\text { QX-like: } \\
\text { TC07-1 }\end{array}$}} & \multirow{2}{*}{\multicolumn{2}{|c|}{$\begin{array}{l}\text { 793/B-like: } \\
\text { IBV Variant } 1\end{array}$}} & \multirow{2}{*}{\multicolumn{2}{|c|}{$\begin{array}{l}\text { IS/1496/06: } \\
\text { IBV Variant } 2\end{array}$}} & \multirow{2}{*}{\multicolumn{2}{|c|}{ TC07-2 }} & \multirow{2}{*}{\multicolumn{2}{|c|}{ Q1: Italy/11 }} & \multirow{2}{*}{\multicolumn{2}{|c|}{ Italy 02}} & \multicolumn{4}{|c|}{ Mass } \\
\hline & & & & & & & & & & & & & & & \multicolumn{2}{|c|}{ Mass Avial } & \multicolumn{2}{|c|}{ Egypt F03 } \\
\hline & $\$$ & $\S$ & $*$ & $\S$ & * & $\S$ & * & $\S$ & 4 & $\S$ & $*$ & $\S$ & $\$$ & $\S$ & $\$$ & $\S$ & $*$ & $\S$ \\
\hline CK/ZA/3665/11 & 97.3 & 99.0 & $98.0 \dagger$ & $97.9 \dagger$ & 77.6 & 89.0 & 76.5 & 87.3 & 66.1 & 72.1 & 76.3 & 86.4 & 77.8 & 87.6 & 78.1 & 88.2 & 78.4 & 88.0 \\
\hline CK/ZA/4916/11 & $97.5 \dagger$ & $98.5 \dagger$ & 95.1 & 97.6 & 78.0 & 89.0 & 76.8 & 87.8 & 66.1 & 72.6 & 76.6 & 86.4 & 78.2 & 88.0 & 78.2 & 88.3 & 78.61 & 88.1 \\
\hline $\mathrm{CK} / \mathrm{ZA} / 4871 / 12$ & $97.3 \dagger$ & $98.5 \dagger$ & 95.1 & 97.6 & 78.1 & 89.2 & 76.8 & 87.6 & 66.4 & 72.1 & 76.6 & 86.7 & 78.0 & 87.1 & 78.2 & 87.8 & 78.6 & 87.6 \\
\hline CK/ZA/6720/12 & $97.1 \dagger$ & $98.1 \dagger$ & 94.8 & 96.9 & 78.4 & 88.5 & 78.2 & 86.6 & 65.6 & 71.8 & 77.5 & 86.1 & 78.8 & 87.1 & 79.2 & 97.5 & 79.9 & 87.3 \\
\hline CK/ZA/3190/11 & 78.1 & 87.5 & 78.0 & 88.1 & 77.5 & 85.0 & 80.4 & 86.1 & 65.5 & 72.3 & 77.6 & 84.1 & 77.9 & 84.5 & $99.0 \dagger$ & $96.5 \dagger$ & 97.2 & 95.1 \\
\hline CK/ZA/3809/11 & 78.3 & 87.8 & 78.1 & 88.2 & 77.7 & 85.2 & 80.5 & 86.4 & 65.4 & 72.8 & 77.8 & 84.3 & 78.1 & 84.8 & $99.5 \dagger$ & $96.5 \dagger$ & 97.7 & 94.8 \\
\hline CK/ZA/3418/11 & 78.5 & 87.6 & 78.3 & 88.1 & 77.9 & 85.0 & 80.4 & 86.2 & 65.4 & 72.6 & 78.0 & 84.0 & 78.4 & 84.5 & $99.6+$ & $96.5 \dagger$ & 97.7 & 94.9 \\
\hline CK/ZA/5250/11 & 78.5 & 87.8 & 78.3 & 88.2 & 77.8 & 85.2 & 80.7 & 86.4 & 65.6 & 72.8 & 77.9 & 84.3 & 78.3 & 84.8 & $99.7 \dagger$ & $96.7 \dagger$ & 97.9 & 95.1 \\
\hline CK/ZA/5315/11 & 78.5 & 87.8 & 78.3 & 88.2 & 77.7 & 85.2 & 80.6 & 86.4 & 65.5 & 72.8 & 77.9 & 84.1 & 78.2 & 84.8 & $99.7 \dagger$ & $96.7 \dagger$ & 97.8 & 95.1 \\
\hline CK/ZA/5815/11 & 78.4 & 87.4 & 78.2 & 87.8 & 77.6 & 84.8 & 80.3 & 85.2 & 65.5 & 72.6 & 77.9 & 84.1 & 78.2 & 83.3 & $99.3 \dagger$ & $96.5 \dagger$ & 97.5 & 94.8 \\
\hline CK/ZA/6776/11 & 78.4 & 87.8 & 78.2 & 88.3 & 77.7 & 85.2 & 80.6 & 86.4 & 65.3 & 72.8 & 77.9 & 84.3 & 78.2 & 84.8 & $99.7 \dagger$ & $96.7 \dagger$ & 97.8 & 95.0 \\
\hline CK/ZA/6621/11 & 78.6 & 87.8 & 78.4 & 88.3 & 77.9 & 85.2 & 80.7 & 86.4 & 65.5 & 72.8 & 77.9 & 84.3 & 78.4 & 84.8 & $99.7 \dagger$ & $96.7 \dagger$ & 97.9 & 95.0 \\
\hline CK/ZA/6516/11 & 78.4 & 87.8 & 78.2 & 88.3 & 77.6 & 85.2 & 80.6 & 86.4 & 65.5 & 72.8 & 77.9 & 84.3 & 78.2 & 84.8 & $99.5 \dagger$ & $96.7 \dagger$ & 97.7 & 95.0 \\
\hline CK/ZA/6742a/11 & 78.4 & 87.6 & 78.2 & 88.1 & 77.7 & 85.0 & 80.5 & 86.2 & 65.5 & 72.8 & 77.9 & 84.3 & 78.2 & 84.5 & $99.6 \dagger$ & $96.5 \dagger$ & 97.7 & 94.8 \\
\hline $\mathrm{CK} / \mathrm{ZA} / 6743 \mathrm{~b} / 11$ & 78.1 & 87.8 & 77.9 & 88.3 & 77.4 & 85.2 & 80.2 & 86.4 & 65.1 & 72.8 & 77.5 & 84.3 & 77.9 & 84.8 & $99.2 \dagger$ & $96.7 \dagger$ & 97.4 & 95.0 \\
\hline CK/ZA/6689/12 & 78.5 & 87.8 & 78.3 & 88.3 & 77.8 & 85.2 & 80.7 & 86.4 & 65.5 & 72.8 & 77.9 & 84.3 & 78.3 & 84.8 & $99.7 \dagger$ & $96.7 \dagger$ & 97.9 & 95.0 \\
\hline CK/ZA/0890/81 & 78.5 & 87.8 & 78.3 & 88.3 & 77.8 & 85.2 & 80.7 & 86.4 & 65.5 & 72.8 & 77.9 & 84.3 & 78.3 & 84.8 & 99.7 & 96.7 & 97.9 & 95.0 \\
\hline
\end{tabular}

$\dagger$, Denotes highest comparitive similarity in study, $\$$, Nucleotide sequence identity of the 1460 bp sequence; $\S, 427$ amino acid translation similarity.

The use of especially the live day-old H120 vaccine and the close similarity of Mass-type isolates to H120 must not be overlooked as the most likely influence on the prevalence of the H120 group. This implies that the most likely contributors to IBV serotypes within these flocks are Mass-type live vaccines. However, there is the possibility that either through genetic drift or quasi-species selection, field-adapted virulent Mass-type IBV was able to proliferate in suitable hosts. The basis of this statement is that all the samples collected were from clinical cases of respiratory disease and the presence of suggestive pathology on postmortem examination. Recombination and reversion to virulence within Mass-type IBV vaccines have been described and field experience over the years of use has found that poor vaccination technique, concurrent viral or bacterial infections as well as on-farm management conditions can lead to IBV pathology in light of vaccine usage (Cavanaugh, Davis \& Cook 1992).

Variability within the QX-like genotype was greater at $97.7 \%$ - 98.5\% than that seen in the Mass grouping at $99.0 \%-99.7 \%$. A temporal trend in genetic drift was observed. This observation is in contrast to evolutionary patterns within the Mass group and supports the existence of genetic drift within this IBV subpopulation. The greatest similarity was noted when comparing it to the QX-like strains of European origin (97\%) as opposed to the Asian QX-like strains (94\%), which provides circumstantial evidence of the spread of QX-like IBV from Asia into Europe and then downward into Africa.

The results of the KZN isolates would support the high host adaptability of the QX-like variant and identify it as the leading 'variant' within KZN poultry flocks.

Shaw, Britton and Cavanaugh (1996) investigated Belgian nephrotropic IBV strains and reported that the S1 gene differed by $21 \%-45 \%$ from vaccine strains whilst the S2 gene only had $10 \%-12 \%$ differentiation. The $793 / \mathrm{B}$ strain was shown to display between $21 \%$ and $25 \%$ variation amongst field isolates, whilst still retaining the same serotype (Adzhar \& Gough 1997). The CK/CH/LDL/971 strain of IBV was shown to have $<80 \%$ homology between the vaccine and pathogenic strain as well as between itself and other IBV types (Liu et al. 2009). Host-driven selection has been postulated and can occur as demonstrated during egg passage of several 793/B isolates; although this selection did not alter the pathogenicity, it does illustrate the quasispecies theorem regarding IBV populations (Cavanaugh et al. 2005). Jackwood, Hilt and Callison (2003) utilised real-time PCR techniques and melting curves to visualise the existence of quasi-species within the IBV Beaudette strain. Re-isolated virus has been demonstrated to contain subpopulations, again supporting the quasi-species theorem (McKinley, Hilt \& Jackwood 2008).

The correlation between QX-like serotypes and the actual sequence was inconsistent, as only 4 of the 11 serotype QXlike isolates were classified within the QX-like genotype. All seven remaining Mass serotypes genotyped into the same group. By comparison, when examining partial S1 gene sequence data, none of the QX-like partial sequences were serotyped as QX-like. Seven serotype QX-like isolates genotyped as Mass, whilst the two isolates that did not fall into a known serotype at the time were split between the Mass and QX-like genotype. The above results cast doubt on the correlation between serotype and genotype results. It has been described that small sequence variations may alter the virus neutralising epitope and thereby the serotype of the virus (Cavanaugh et al. 1992). An alternative hypothesis could be that coinfection with multiple strains of IBV is responsible for clinical disease, and between the culture or 
serum neutralisation test and the subsequent successive passages and RT-PCR selection for host-specific strains there is selection for an alternate dominant strain (Liu et al. 2009; $\mathrm{Xu}$ et al. 2007). Comparing these protein sequences to the isolates that both genotyped and serotyped as Massachusetts, there is no obvious genetic marker that serotyped as QX-like in contrast to the group that serotyped as Mass-like.

\section{Conclusion}

This study describes the isolation, identification and serotyping of a representative selection of IBV, predominantly in KwaZulu-Natal, between 2011 and 2012. The Massachusetts (H120) serotype was the most prevalent serotype within the KZN poultry flock, according to the samples analysed in this study. The evidence suggested that the most commonly isolated Mass-types are primarily derived from variation or mutation of vaccine strains administered to flocks. The QXlike serotype is the only non-vaccine serotype identified in the sample pool and had a greater degree of variation within the group than the Mass-type isolates. The presumption therefore is that greater genotypic variation is seen amongst IBV serotypes that are not exposed to vaccine selective pressure.

\section{Acknowledgements}

We thank Ms Annemarie Bosman for advice, Dr Nokuthula Ntseki and Rainbow Chicken Farms for the use of historical isolates and financial support of the study and Drs Jaco Goosen and Andrew van Wijk for the submission of additional isolates. We would like to thank the Institute for Tropical Medicine, Antwerp, Belgium for the funding of this study.

\section{Competing interests}

The authors declare that they have no financial or personal relationships that may have inappropriately influenced them in writing this article.

\section{Authors' contributions}

A.D.K. (Rainbow Chicken Farms) and C.A. (University of Pretoria) were responsible for experimental and project design. A.D.K. performed most of the experiments. N.M. (Rainbow Chicken Farms) performed the initial viral isolation and serum neutralisation.

\section{References}

Adzhar, A. \& Gough, R.E., 1997, 'Molecular analysis of the 793/b serotype of infectious bronchitis virus in Great Britain', Avian Pathology 26, 625.http://dx.doi. org/10.1080/03079459708419239

Boursnell, M.E.G., Brown, T.D.K., Foulds, I.J., Green, P.F., Tomley, F.M. \& Binns, M.M., 1987, 'Completion of the sequence of the genome of the coronavirus avian infectious bronchitis virus', Journal of General Virology 68, 57-77. http://dx.doi. org/10.1099/0022-1317-68-1-57

Cavanaugh, D., 2001, 'A nomenclature for avian coronavirus isolates and the question of species status', Avian Pathology 30, 109-115. http://dx.doi. org/10.1080/03079450120044506

Cavanaugh, D., Davis, P.J. \& Cook, J.K.A., 1992, 'Infectious bronchitis virus: Evidence for recombination within the Massachusetts serotype', Avian Pathology 21(3), 401-408. http://dx.doi.org/10.1080/03079459208418858
Cavanaugh, D., Davis, P.J., Cook, J.K.A., Li, D., Kant, A. \& Koch, G., 1992, 'Location of the amino acid differences in the S1 spike glycoprotein subunit of closely related
serotype of infectious bronchitis virus', Avian Pathology 21(1), 33-43. http:// serotype of infectious bronchitis virus',
dx.doi.org/10.1080/03079459208418816

Cavanaugh, D., Davis, P.J. \& Mockett, A.P.A., 1988, 'Amino acids within the hypervariable region 1 of avian coronavirus IBV (Massachusetts serotype) spike glycoprotein are associated with neutralization epitopes', Virus Research 11, 141-150. http://dx.doi.org/10.1016/0168-1702(88)90039-1

Cavanaugh, D. \& Naqi, S.A., 1997, 'Infectious bronchitis', in B.W. Calnek (ed.), Diseases of poultry, 10th edn., vol. 18, pp. 511-527, lowa State University Press, Ames.

Cavanaugh, D., Picault, J.P., Gough, R.E., Hess, M., Mawditt, K. \& Britton, P., 2005, 'Variation in the spike protein of the 793/B type of infectious bronchitis virus, in the field and during ultimate passage in chickens and embryonated eggs', Avian Pathology 34(1), 20-25. http://dx.doi.org/10.1080/03079450400025414

Cook, J.K.A., 1983, 'Isolation of a new serotype of infectious bronchitis-like virus from chickens in England', Veterinary Record 112,104-105. http://dx.doi.org/10.1136/ vr.112.5.104

Cook, J.K.A., Huggins, M.B. \& Ellis, M.M., 1991, 'Use of an infectious bronchitis virus and Escherichia coli model infection to assess the ability to vaccinate successfully against infectious bronchitis in the presence of maternally-derived immunity', Avian Pathology 20, 619-626. http://dx.doi.org/10.1080/03079459108418801

Cook, J.K.A., Orbell, S.J., Woods, M.A. \& Huggins, M.B., 1999, 'Breadth of protection of the respiratory tract provided by different live-attenuated infectious bronchitis vaccines against challenge with infectious bronchitis viruses of heterologous serotypes', Avian Pathology 28, 477-485. http://dx.doi. org/10.1080/03079459994506

De Herdt, P., Ducatelle, R., Uyttebroek, E., Sneep, A. \& Torbeyns, R., 2001, 'Infectious bronchitis serology in broilers and broiler breeders: Correlations between antibody titres and performance in vaccinated flocks', Avian Diseases 45 , 612-619. http://dx.doi.org/10.2307/1592902

De Wit, J.J., Cook, J.K.A. \& Van der Heijden, H.M.J.F., 2011, 'Infectious bronchitis virus variants: A review of the history, current situation and control measures', Avian Pathology 40(3), 223-235. http://dx.doi.org/10.1080/03079457.2011.566260

Dhinakar Raj, G. \& Jones, R.C., 1997, 'Infectious bronchitis virus: Immunopathogenesis of infection in the chicken', Avian Pathology 26, 677-706. http://dx.doi. org/10.1080/03079459708419246

Gelb, J. Jnr., 1989, 'Infectious bronchitis', in H.G. Purchase, L.H. Arp, C.H. Domermuth \& J.E. Pearson (eds.), A laboratory manual for the isolation and identification of avian pathogens, 3rd edn., pp. 124-127, American Association of Avian of avian pathogens, 3rd edn., pp.
Pathologists, Kendall Hunt, Dubuque.

Hall, T.A., 1999, 'BioEdit: A user-friendly biological sequence alignment editor and analysis program for Windows 95/98/NT', Nucleic Acid Symposium Series 41, 95-98.

Ignjatovic, J. \& Galli, L., 1994, 'Immune responses to structural proteins of avian infectious bronchitis virus', Avian Pathology 24, 313-332. http://dx.doi. org/10.1080/03079459508419072

Jackwood, M.W., 2012, 'Review of infectious bronchitis virus around the world', Avian Diseases 56, 634-641. http://dx.doi.org/10.1637/10227-043012-Review.1

Jackwood, M.W., Hilt, D.A. \& Callison, S.A., 2003, 'Detection of infectious bronchitis virus by real-time reverse transcriptase-polymerase chain reaction and virus by real-time reverse transcriptase-polymerase chain reaction and
identification of a quasispecies in the Beaudette strain', Avian Diseases 47 identification of a quasispecies in the
$718-724$. http://dx.doi.org/10.1637/6075

Jungherr, E.L., Chomiak, T.W. \& Luginbuhl, R.E., 1956, 'Immunologic differences in strains of infectious bronchitis virus', Proceedings of the 60th Annual Meeting of the US Livestock Association, Chicago, pp. 203-209.

Kant, A., Koch, G., Van Roozelaar, D.J., Kusters, J.G., Poelwijk, F.A.J. \& Van der Zeijst B.A.M., 1992, 'Location of the antigenic sites defined by neutralizing monoclonal antibodies on the S1 avian infectious bronchitis virus glycopolypeptide', Journal of General Virology 73, 591-596. http://dx.doi.org/10.1099/0022-1317-73-3-591

Koch, G., Hartog, L., Kant, A. \& Van Roozelaar, D.J., 1990, 'Antigenic domains on the peplomer protein of avian infectious bronchitis virus: Correlation with biological functions', Journal of General Virology 71, 1929-1935. http://dx.doi. org/10.1099/0022-1317-71-9-1929

Lee, C. \& Jackwood, M.W., 2001, 'Origin and evolution of Georgia 98 (GA98), a new serotype of avian infectious bronchitis virus', Virus Research 80, 33-39. http:// dx.doi.org/10.1016/S0168-1702(01)00345-8

Liu, S., Zhang, X., Gong, L., Yan, B., Li, C., Han, Z. et al., 2009, 'Altered pathogenicity, immunogenicity, tissue tropism and 3-7 kb region sequence of an avian infectious bronchitis coronavirus strain after serial passage in embryos', Vaccine 27 4630-4640. http://dx.doi.org/10.1016/j.vaccine.2009.05.072

McKinley, E.T., Hilt, D.A. \& Jackwood, M.W., 2008, 'Avian coronavirus infectious bronchitis attenuated live vaccines undergo selection of subpopulations and mutations following vaccination', Vaccine 26, 1274-1284. http://dx.doi. org/10.1016/j.vaccine.2008.01.006

McKinley, E.T., Jackwood, M.W., Hilt, D.A., Kissinger, J.C., Robertson, J.S., Lemke,C. et al., 2011, 'Attenuated live vaccine usage affects accurate measures of virus diversity and mutation rates in avian coronavirus infectious bronchitis virus', Virus Research 158, 225-234. http://dx.doi.org/10.1016/j.virusres.2011.04.006

Meulemans, G., Boschmans, M., De Caesstecker, M., Van den Berg, T.P., Denis, P. \& Cavanaugh, D., 2001, 'Epidemiology of infectious bronchitis virus in Belgian broilers: A retrospective study, 1986 to 1995', Avian Pathology 30, 411-421. http://dx.doi.org/10.1080/03079450120066412

Mondal, S.P. \& Naqi, S.A., 2001, 'Maternal antibody to infectious bronchitis virus: Its role in protection against infection and development of active immunity to vaccine', Veterinary Immunology and Immunopathology 79, 31-40. http://dx.doi. org/10.1016/S0165-2427(01)00248-3

Morley, A.J. \& Thompson, D.K., 1984, 'Swollen-head syndrome in broiler chickens', Avian Diseases 28, 238-243. http://dx.doi.org/10.2307/1590147 
Perdue, M.L. \& Seal, B.S., 2000, 'Impact of avian viruses', Viral Ecology 12, 549-591. http://dx.doi.org/10.1016/B978-012362675-2/50016-1

Shaw, K., Britton, P. \& Cavanaugh, D., 1996, 'Sequence of the spike protein of the Belgian B164S isolate of nephropathogenic infectious bronchitis virus', Avian Pathology 25(3), 607-611. http://dx.doi.org/10.1080/03079459608419165

Spaan, W., Cavanaugh, D. \& Horzinek, M.C., 1988, 'Coronaviruses: Structure and genome expression', Journal of General Virology 69, 2939-2952. http://dx.doi. org/10.1099/0022-1317-69-12-2939

Tamura, K., Peterson, D., Peterson, N., Stecher, G., Nei, M. \& Kumar, S., 2011, 'MEGA5 Molecular evolutionary genetics analysis using maximum likelihood, evolutionary distance, and maximum parsimony method', Molecular Biology and Evolution 28, 2731-2739. http://dx.doi.org/10.1093/molbev/msr121
Toro, H., Van Santen, V.L. \& Jackwood, M.W., 2012, 'Genetic diversity and selection regulates evolution of infectious bronchitis virus', Avian Diseases 56, 449-455. http://dx.doi.org/10.1637/10072-020212-Review.1

South African Poultry Association, 2012, SAPA Industry Profile, viewed 15 September 2013, from http://www.sapoultry.co.za/industry_profile.php

Wang, L., Xu, Y. \& Collisson, E.W., 1997, 'Experimental confirmation of recombination upstream of the S1 hypervariable region of infectious bronchitis virus', Virus Research 49, 139-145. http://dx.doi.org/10.1016/S0168-1702(97)01466-4

Xu, C., Zhao, J., Hu, X. \& Zhang, G., 2007, 'Isolation and identification of four infectious bronchitis virus strains in China and gene', Veterinary Microbiology 122, 61-71. http://dx.doi.org/10.1016/ j.vetmic.2007.01.006 